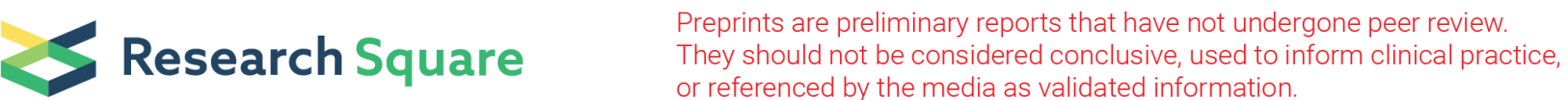

\section{Experimental Study on the Reliability and the Precision-maintenance of the Ultra-precision Grinding Machine Based on the Key Subsystem Platforms}

\author{
Pengli Lei ( $916875407 @ q q . c o m$ ) \\ Xiamen University \\ Zhenzhong Wang \\ Xiamen University \\ Chenchun Shi \\ Xiamen University \\ Yunfeng Peng \\ Xiamen University \\ Feng Lu \\ Xiamen University \\ Zuhui Liu \\ Xiamen University
}

\section{Research Article}

Keywords: Reliability technology, Thermal characteristics, Ultra-precision machine tools, Hydrostatic spindle

Posted Date: August 11th, 2021

DOl: https://doi.org/10.21203/rs.3.rs-772762/v1

License: (c) (i) This work is licensed under a Creative Commons Attribution 4.0 International License. Read Full License

Version of Record: A version of this preprint was published at The International Journal of Advanced Manufacturing Technology on November 15th, 2021. See the published version at https://doi.org/10.1007/s00170-021-08314-6. 


\section{Abstract}

The development of high-reliability, high-precision large-scale CNC ultra-precision grinding machines is essential for the efficient processing and manufacturing of large-diameter optical components. In this paper, we studied the reliability and the precision-maintenance of the ultra-precision grinding machine tool experimentally. First, the subsystems with poor performance was identified based on former operating data, which turned out to be the hydrostatic spindle subsystem and the feed subsystem. Then, we set up specific experimental platforms for these two subsystems in order to study the thermal deformation and thermal characteristics. The temperature difference between the inflow and outflow oils of the hydrostatic systems is used as the key parameter to model the accuracy evolution. Our results may provide a method to reveal the relationship between the thermal characteristics and the operating parameters of the subsystems, an therefore compensate the thermal error of the whole ultra-precision grinding machine.

\section{Introduction}

Large-diameter aspherical components are widely used in high-tech applications such as aerospace, military industrial optics and laser technology ${ }^{[1-3]}$, while the ultra-precision processing of large-diameter optical components is a complex systematic project involving precision machine tools, numerical control, processing technology and process, precision inspection and compensation control. Nowadays, "efficient grinding \& deterministic polishing" has become a feasible technology development trend in the field of large-diameter optical manufacturing. Therefore, the research and development of ultra-precision grinding machine tools are of great significance to meet the high-efficiency processing and production of largediameter optical components ${ }^{[4-5]}$.

The various machining errors of ultra-precision machine tools directly affect the machining accuracy of the processed components. Among them, thermal error occupies a large proportion of the workpiece machining error, and the thermal deformation of the machine tool has become the main source of error in the precision and ultra-precision machining process ${ }^{[6-9]}$. For processing large-diameter optical components, especially components with a diameter of $1.5 \mathrm{~m}$ or more, the processing time usually exceeds 10 hours when the material removing depth is $1 \mathrm{~mm}^{[5]}$. For long-running machine tools, especially in ultra-precision machining, the machining error caused by the thermal deformation will be very significant. Therefor there are higher requirements for the reliability of the machine tools. There have been a lot of research work and results on the reliability and accuracy retention of machine tools ${ }^{[10-12]}$. Setting up specific experimental platforms for the key parts of the machine tool is also an effective method for the research on the subsystems of the whole machine ${ }^{[13]}$.

Hydrostatic technology was widely utilized for the optical grinding machine tools 2MK1760 and UPG80 previously developed by our research group ${ }^{[14-17]}$, to ensure the overall high rigidity and high load-bearing characteristics of the machine tools. In this paper, the research on reliability and accuracy retention of the grinding machine tools mentioned above has been carried out, especially two experimental platforms of 
hydrostatic spindle and hydrostatic guideway has been set up. Through a series of experiments on the experimental platforms, we focused on the impact of thermal effects on the accuracy of the moving parts of the subsystems. By collecting the operating data of the existing grinding machines, the reliability of the whole machine is analyzed at first. Subsequently, with the temperature data monitored on the key subsystem experimental platforms, the temperature difference between the inflow and outflow oils of the hydrostatic systems is used as the key parameter to model the accuracy evolution.

\section{Methods And Experimental Setup}

\subsection{Research on the reliability of the grinding machine}

The whole machine is divided into 8 subsystems, each with its own independent structure and function. The details are shown in Table 1. After collecting and grouping the operating data, the reliability analysis of the ultra-precision grinding machine can be carried out.

We collected and classified around 30 pieces of data. According to the subsystems grouping shown in Table 1, the frequency of operational failures of each subsystem are obtained, sorted by the frequency from high to low, as shown in Fig. 1(a).

Combining Table 1 and Fig. 1, the subsystems with the highest frequency of operational failure are the electronic control system, the spindle system and the feed system. However, unlike ordinary machine tools, ultra-precision CNC grinding machines have the characteristics of relatively concentrated failures due to their high reliability and fewer failure samples. Taking the result of Fig. 1 as an example, the failure of the electronic control system accounts more than $70 \%$ of the total data, so the reliability level of the electronic control system should be emphasized in the improvement design of the machine. The failure frequency of other subsystems is low, and the current reliability level can be maintained when the design is improved as well as the manufacturing cost is considered comprehensively.

The specific analysis result of the failure of the electronic control system is shown in Fig. 1(b). Which reveals that the disconnection of the circuit wiring of the moving parts and the damage of the relay are the main reasons for the failure of the electronic control system. Therefore, when designing a new machine tool, design optimization is required to reduce the probability of failure and improve reliability.

In view of the characteristics of CNC grinding machines, we designed the score distribution factors that affect the reliability of ultra-precision grinding machines, including: complexity, technical level, operating hours, environmental conditions, and the degree of impact of subsystem maintenance on the performance of the whole machine. The score range is $1-10$, and the higher the score, the worse the reliability.

After designing the form, 14 relevant experts including machine tool manufacturers, machine tool users, and research units were invited to score, and the scoring data of each factor was removed from the 
maximum and minimum values, and then the average value was obtained. The statistical results are shown in Table 2.

Based on the statistical data above, the scores and score coefficients of each subsystem can be calculated:

$$
\begin{aligned}
\omega_{i} & =\prod_{j=1}^{5} r_{i j} \\
\omega & =\sum_{i}^{n} \omega_{i} \\
C_{i} & =\omega_{i} / \omega
\end{aligned}
$$

$C_{i}$-The score coefficient of the i-th subsystem

$\omega_{i}$-The scores for the i-th subsystem

$\omega$-The scores for the whole machine

$r_{i j}$-The scores for the i-th unit, j-th factor

After obtaining the scores and the score coefficients, the relationship between the failure rate and the failure-free time of the entire machine is shown in the following formula, according to the exponential distribution of the entire life of the machine. Subsequently, the total MTBF of the whole machine is 2,000 hours as the goal to reverse the calculation, and the reliability time results of each subsystem based on the scoring distribution method can be obtained as shown in Table 3.

$$
\begin{gathered}
M T B F=1 / \lambda_{S} \\
\lambda_{i}=C_{i} \times \lambda_{s}
\end{gathered}
$$

$\lambda_{s}--$ Reliability index of the whole machine

$\lambda_{i}--$ Failure rate of each subsystem

Based on the reliability distribution results of each subsystem in the table above, it can be seen that the spindle system, feed system are the two lowest score systems in order. Generally, the subsystem with lower reliability is easier to upgrade than the subsystem with higher reliability and does not take up more resources and costs. From this perspective, improving the reliability of the two subsystems can be used as a priority means to improve the reliability of the whole machine. Therefore, more attention should be payed to the above two subsystems. 
On the other hand, the accuracy retention of the spindle system and the feed system is also a key technology in the design and manufacture of ultra-precision grinding machine tools. Therefore, we have established reliability and accuracy retention experimental research platforms for the two subsystems of the appeal for further study.

\subsection{Subsystem experimental platforms}

The spindle system experimental platform: The spindle system directly supports the movement of the grinding wheel during the machining process, which should have the basic requirements of high rotation accuracy, long precision life, sufficient rigidity, low heat generation, and no vibration. By analyzing the movement and force of the hydrostatic spindle under the actual operating state, we have developed an experimental platform for the hydrostatic spindle to study the reliability and the thermal error of the spindle, which is shown in figure 2.

The experiment is divided into two parts, non-loaded and loaded progress, as shown in Fig. 2. Since the data of thermal error has always been an important part of the research on thermal error compensation of machine tools, which is also the basis of thermal error compensation. The thermal error of the spindle is caused by the temperature change of the inner and outer structure of the spindle. Therefor, the axial thermal displacement error is measured by a laser displacement sensor, as shown in Fig. 2(a). The temperature of the spindle is detected by arranging an appropriate number of temperature sensors (PT100 thermal resistance) on the spindle experiment platform. The temperature sensors are grouped and shown in Table 4:

Figure 2(b) shows the loading experiment settings. Among them, the axial force and radial force loaded on the spindle is set by a pair of piezoelectric actuators, which are preload to make up for the shortcomings of the small moving distance, and the loading value is collected through a pressure sensor. Then, the torque is loaded by a magnetic powder brake, and is connected to the torque sensor and the spindle axis through a coupling.

All experiment is carried out under an isolated constant temperature condition to avoid interference to the temperature monitoring data of the spindle.

The feed system experimental platform: The hydrostatic guideway has a wide range of applications in the feed system of ultra-precision machine tools. It uses high-pressure oil film to realize pure liquid friction during movement, and has many advantages such as long life, high precision, high rigidity, large bearing capacity and good vibration resistance. We have designed a single-axis high-precision hydrostatic guideway reliability and accuracy retention verification platform, through which we can monitor and measure the temperature, displacement and motion error of the worktable during the experiment. The platform is shown in figure 3 :

The temperature data of the key distribution points of the hydrostatic guideway platform is measured by temperature sensors, and the motion straightness of the worktable is measured by a Renishaw laser 
aligner. The platform is equipped with a hydraulic station system and a hydrostatic oil cooling circulation system.

\section{Results And Discussion}

\subsection{Unloaded experiment of the spindle system}

Under non-loaded conditions, the spindle was running continuously at different speeds with temperature monitored. The continuous experiment contains five rotating speed stages: $0 \mathrm{rpm}, 500 \mathrm{rpm}, 1000 \mathrm{rpm}$, $1500 \mathrm{rpm}$, and 2000rpm. Each stage has a running time of 1 hour to ensure that the temperature change of the spindle at each rotating speed can be stabilized. The result is shown in Fig. 4.

It can be seen from the temperature monitoring graph that, in addition to the ambient temperature, each part of the spindle system will have an obvious initial temperature rise after the experiment is turned on, even if the rotating speed is $0 \mathrm{rpm}$. The temperature of each measuring point on the spindle shows a stepped upward trend with the increase of the rotating speed. We extracted the oil temperature difference of the front bearing, the rear bearing and the motor part of the spindle system, and made the curve shown in Fig. 5, which can further reveals the law of temperature rise in each part of the spindle.

Figures 5(a), 5(b), and 5(c) respectively represent the data of the temperature difference between oil inflow and outflow at the position of the front bearing, the rear bearing and the motor part. The results show that the different characteristic temperature rising in different areas of the spindle. The temperature difference in the front bearing responds relatively rapid, which can be fitted as a quadratic curve with the rotating speed. On the contrary, the temperature change in the rear bearing is closer to a linear growing. The temperature difference between the inlet and outlet of the motor's cooling oil is lower than that of the bearing, but it also shows a linear growing with the increase in rotating speed.

\subsection{Axial thermal error of the spindle}

In the experiment, the temperature data and displacement data were collected at a specific rotating speed. The axial thermal displacement with temperature data of the spindle at speed of $1000 \mathrm{rpm}$, 2000rpm, and 3000rpm were recorded respectively, as shown in Fig. 6:

The experiment was carried out for one and a half hours in each speed group until the temperature of the spindle stabilized. The thermal displacement data is collected every three minutes with the laser displacement sensor at a sampling rate of $1000 \mathrm{~Hz}$, as shown in Fig. 6 (a), Fig. 6 (b), and Fig. 6 (c). Overall, displacement data at 3000rpm corresponds to the largest thermal error in the equilibrium state, where the axial thermal error reaches $40 \mu \mathrm{m}$. The thermal error at the rotating speed of 1000rpm is the smallest, which is $8 \mu \mathrm{m}$.

In order to explore the influence of the temperature change on the thermal error of the spindle system, also to find the linear or non-linear relationship between the key temperature data and the thermal error of 
the spindle, it is necessary to establish a prediction of the thermal error of the machine tool spindle with high accuracy, strong generalization ability, and small calculation amount. Common thermal error modeling methods include: multiple linear regression (MLR), artificial neural network (ANN), gray prediction model (GM), support vector machine (SVM), etc. ${ }^{[18-20]}$

Here we have chosen the SVM regression model with Gaussian kernel, and utilized the experimental data of the spindle at a rotating speed of $1000 \mathrm{rpm}, 2000 \mathrm{rpm}$, and $3000 \mathrm{rpm}$ as the input of the training data set, and the corresponding thermal displacement as the output. Therefore, there are 88 sets of temperature-thermal displacement data in the training set in total.

Subsequently, by inputting the experimental data of the spindle at a rotating speed of 2500rpm into the trained model, the thermal displacement prediction curve can be obtained, as shown in Fig. 6(d). It can be seen that the model has a certain thermal error prediction effect, whose maximum prediction error is $2 \mu \mathrm{m}$. Therefore, in the case of small batches of data obtained under experimental conditions, SVM regression model can obtain sufficiently accurate thermal error predictions.

\subsection{Preloaded experiment of the spindle system}

In this section, we have carried out experiments on the temperature difference evolution of the hydrostatic spindle under the load of torque and radial force under simulated working conditions, and explored the effect of different loading parameters to the temperature rising.

Among them, the detail of the radial loading unit is shown in Fig. 7, including a pair of piezoelectric actuators, pressure sensors, charge amplifiers and signal collector. Piezoelectric ceramics are set for sinusoidal excitation with no bias voltage. The pressure load signal is collected by a pressure sensor preloaded in series with the piezoelectric actuators. The spindle torque is loaded by the magnetic powder brake. At the rotating speed of $100 \mathrm{rpm}$. The magnetic powder brake with $600 \mathrm{w}$ rated power corresponds to a maximum torque output of $57.3 \mathrm{Nm}$, so the maximum torque output of $60 \mathrm{Nm}$ can be used for loading, since the empirical value of the grinding wheel torque is usually $20-70 \mathrm{Nm}$. Before each test, the spindle system has been warmed up till the temperature is stabilize. The output torque of the magnetic powder brake is set from $0 \mathrm{Nm}$ to $60 \mathrm{Nm}$, while the temperature rising information of the spindle under the corresponding working conditions is collected.

By analyzing the temperature difference between the inlet and outlet oil, as shown in Fig. 7(a), it is promising to infer that under the condition of a fixed rotating speed, the temperature rise of the spindle under different torques is mainly reflected in the motor, and the bearing temperature change is not greatly affected by the torque loading. Since the motor heat is directly proportional to the output power, and the output power will increase with the increase of the load torque, the temperature difference between the oil input and output of the motor will increase stepwise under different torque loads. The overall temperature rise curve of the motor also shows a step-like upward trend, as shown in Fig. 7(b). 
In the experiment, the temperature rise trend of the motor basically conforms to the quadratic curve fitting, and the temperature rise curve is basically the same under different radial force loading as long as the torque loading condition remains the same, which indicated that the radial force has little effect on the motor temperature rise within the usual range, while torque is the main source of thermal power.

\subsection{Experiment of hydrostatic guideway system}

In this experiment, nine temperature measurement points are set up at both the hydrostatic guideway and the hydraulic station, including: rail oil inlet, rail oil outlet, rail base, workbench, hydraulic station oil outlet, hydraulic station oil inlet, and cooler outlet, cooler inlet, the air. A temperature sensor is arranged at each point for data collection during the experiment. The time set for the experiment is 5.5 hours, and the temperature change is monitored during the experiment. The laser aligner is used to measure the motion straightness of the workbench when starting up and then every half an hour. The progress has been set at a feed speed of $500 \mathrm{~mm} / \mathrm{min}$. The data collected during the experiment is shown in Fig. 8 below.

We extracted the temperature data of 4 key measuring points to make the curve as shown in Fig. 8(a), $\mathrm{T}_{1^{-}}$ $\mathrm{T}_{4}$ respectively represent the guide rail oil inlet, the guide rail oil outlet, the workbench, and the guide rail base. The experimental results indicated that the oil inlet temperature rises rapidly after starting up to about $24^{\circ} \mathrm{C}$, which is $4^{\circ} \mathrm{C}$ higher than the average temperature of room temperature $\left(20^{\circ} \mathrm{C}\right)$, that may become the main source of thermal errors in the feed system. While the measured temperature of the guide rail base and the worktable shows a very slow rise. The low temperature of the oil outlet indicates that the heat energy of the oil is almost completely transferred to the inside of the guide rail.

The change of the motion straightness of the hydrostatic guideway in the whole experiment is shown in Fig. 8(b). Figure 8(c) shows the comparison curve of the vertical error of the hydrostatic rail before and after the experimental progress. It can be indicate from the figure that with the loading process of thermal stress from the oil, the vertical motion error of the workbench which is carried by the hydrostatic guideway increases across the board, due to the thermal deformation of the rail's surface. The vertical motion straightness presents a shape with low ends and high middle. It also shows that the amplitude of motion straightness increases with time, but the shape remains unchanged.

Considering the temperature change data of the experimental process in Fig. 8(a), it is reasonable to believe that the thermal stress of the hydrostatic guideway has a direct effect on the accuracy of the machine tools, and the heat source mainly comes from the temperature rise of the hydraulic oil. With the continuous increase of the running time of the feed system, the oil film temperature of the hydrostatic guideway continues to rise, resulting in a continuous decrease in the straightness accuracy of the moving workbench. Within 5.5 hours of progressing time, under the effect of thermal deformation, the motion straightness of the workbench increased from $1.91 \mu \mathrm{m}$ to $6.11 \mu \mathrm{m}$, as shown in Fig. 8(d). The overall motion accuracy is reduced by about $4 \mu \mathrm{m}$, so that the straightness of the hydrostatic guideway cannot be maintained within a suitable accuracy range. There have been many studies on the relationship between the motion accuracy of the hydrostatic rail and the surface profile of the rail, but it is not the 
focus of this article. The thermal effect of the motion error will be explained with more details in out other research results.

\section{Conclusion}

In conclusion, based on the operating data of existing machine tools, we have identified the weakest subsystems of ultra-precision grinding machines. Therefor, based on reliability requirements and accuracy retention requirements, a series of experiments for the hydrostatic spindle subsystem and the feed subsystem have been carried out, by setting up specific experimental platforms. The temperature data were chosen as a dominate characteristic index that reflects the deteriorate in the accuracy of the subsystem.

It is revealed that the heating rate is directly related to rotating speed of the spindle, and the heating rate at the bearing increases with the rotating speed much higher than that of the motor. On the other hand, the heating rate of the motor is more obviously affected by the torque loaded. Finally, with SVM regression model, we can effectively predict the thermal deformation of the spindle by using the temperature difference data. For the feed subsystem, the motion accuracy of the hydrostatic guide rail is mainly affected by the temperature of the inflowing oil. The motion accuracy of the hydrostatic guide rail will stabilize after a long time since starting up, and the motion accuracy degrades greatly, which requires us to ensure the temperature control of the incoming oil.

\section{Declarations}

Funding: Not applicable.

Conflicts of interest/Competing interests: Not applicable.

Availability of data and material: We declare that some of the data of this study are available within the article.

Code availability: Not applicable.

Ethics approval: Not applicable.

Consent to participate: Not applicable.

Consent for publication: We agree to transfer copyright of this article to the Publisher.

Authors' contributions: Pengli Lei conceived the experiments and prepared the manuscript. Chenchun Shi helped to analyze the data. Zhenzhong Wang and Yunfeng Peng were responsible for the formulation of the overall plan. Feng Lu and Zuhui Liu assisted all the experiments.

\section{References}

1. Guo, Yinbiao; Yang, Wei; Wang, Zhenzhong, et al. Technology and Application of Ultra-precision Machining for Large Size Optic[J]. Journal of Mechanical Engineering, 2013, 049(019):171-178.

2. Jin, Tan; Li, Ping; Xiao, Hang, et al. Research Summary on Precision Grinding Technology Oriented to Achieve High Process Efficiency for Large and Middle-scale Optic[J]. Journal of Mechanical 
Engineering, 2016, 052(009):165-175.

3. Pileri D. Large Optics Fabrication: Technology Drivers And New Manufacturing Techniques[C]// 33rd Annual Techincal Symposium. Current Developments in Optical Engineering and Commercial Optics, 1989.

4. Leadbeater P B , Clarke M , Wills-Moren W J , et al. A unique machine for grinding large, off-axis optical components: the OAGM 2500[J]. Precision Engineering, 1989, 11(4):191-196.

5. Tonnellier $X$, Morantz $P$, Shore $P$, et al. Precision grinding for rapid fabrication of segments for extremely large telescopes using the Cranfield BoX[J]. Proceedings of SPIE - The International Society for Optical Engineering, 2010, 7739.

6. MAYR J, JEDRZEJEWSKI J囚UHLMANN Eखet al.Thermal issues in machine tools[J]. CIRP AnnalsManufacturing Technology $₫ 2012 \varangle 61(2) \otimes 771-791$.

7. Peklenik J , Jerele A . Some Basic Relationships for Identification of the Machining Processes[J]. CIRP Annals - Manufacturing Technology, 1992, 41(1):155-159.

8. Yang $\mathrm{J}$, Shi $\mathrm{H}$, Feng $B$, et al. Thermal error modeling and compensation for a high-speed motorized spindle[J]. INTERNATIONAL JOURNAL OF ADVANCED MANUFACTURING TECHNOLOGY, 2015, 77(58):1005-1017.

9. LIU Kuo; HAN Wei; WANG Yongqing, et al. Review on Thermal Error Compensation for Feed Axes of CNC Machine Tools[J]. Journal of Mechanical Engineering, 57(3):18.

10. Yang, Zhaojun; Chen, Chuanhai; Chen, Fei, et al. Progress in the Research of Reliability Technology of Machine Tools[J]. Journal of Mechanical Engineering, 2013, 49(020):130-139.

11. KELLER A Z\KAMATH A R. Reliability analysis of CNC machine tools[J]. Reliability Engineering $\rrbracket$ $1982 \otimes 3(6) \varangle 449-473$.

12. JEFFREY P K囚STEVEN M CQMARK E O『et al. Reliability of manufacturing equipment in complex environments[J]. Annals of Operations Research $₫ 2011 \otimes 10 \otimes 1-26$.

13. Chi, Yulun, Li, Haolin. Study Machine Tool Spindle Performance Reliability Based on Bayes Method[J]. Journal of System Simulation, 2016(7):1667-1672.

14. Chenchun, Shi, Zhenzhong, et al. Influence of relative difference between paired guide rails on motion accuracy in closed hydrostatic guideways[J]. Journal of Mechanical Science and Technology, 2020, 34(2):631-648.

15. SHI Chenchun;WANG Zhenzhong;PENG Yunfeng, et al. Influence of PM Controller Parameters on Motion Accuracy of Hydrostatic Guideways[J]. Journal of Mechanical Engineering, 2020, v.56(01):171-179.

16. GAO D, ZHENG D, and ZHANG Z. Theoretical analysis and numerical simulation of the static and dynamic characteristics of hydrostatic guides based on progressive mengen flow controller[J]. Chinese Journal of Mechanical Engineering, 2010, 23(6): 709-716.

17. XUE F, ZHAO W, CHEN Y, et al. Research on error averaging effect of hydrostatic guideways[J]. Precision Engineering, 2012, 36(1): 84-90. 
18. Feng J , Tang X, Li Y , et al. Thermal Error Modelling of the Spindle Using Neurofuzzy Systems[J]. Mathematical Problems in Engineering, 2016, 2016(1):1-10.

19. LIY X『YANG J G『GELVIS T囚et al. Optimization of measuring points for machine tool thermal error based on grey system theory[J]. The International Journal of Advanced Manufacturing Technology $\rrbracket$ 2008ه35(7-8) $₫ 745-750$.

20. Li Y, Wang M, Hu Y, et al. Thermal error prediction of the spindle using improved fuzzy-filtered neural networks[J]. Proceedings of the Institution of Mechanical Engineers Part B Journal of Engineering Manufacture, 2016:0954405415590561.

\section{Tables}

Table 1

Subsystem division of ultra-precision grinding machine

\begin{tabular}{|c|c|c|}
\hline $\begin{array}{l}\text { Subsystem } \\
\text { code }\end{array}$ & $\begin{array}{l}\text { Subsystem } \\
\text { name }\end{array}$ & The main components of the subsystem \\
\hline S01(BS) & Basic system & $\begin{array}{l}\text { bed, worktable, electromagnetic chuck, guide rails, adjustment pad, } \\
\text { slider and other basic supports. }\end{array}$ \\
\hline S02(SD) & $\begin{array}{l}\text { Spindle } \\
\text { system }\end{array}$ & $\begin{array}{l}\text { dynamic balancer, grinding wheel, flange, spindle, front and rear } \\
\text { radial bearings, spindle motor, spindle box, spindle static hydraulic } \\
\text { system, etc. }\end{array}$ \\
\hline S03(FD) & Feed system & $\begin{array}{l}\text { x/y/z axis: motor, pulley, expansion sleeve, ball screw, grating } \\
\text { feedback system, hydrostatic guide,etc. }\end{array}$ \\
\hline S04(LD) & $\begin{array}{l}\text { Hydraulic } \\
\text { system }\end{array}$ & hydraulic pump, oil pipe, sealing ring, flow valve, oil inlet \\
\hline S05(CL) & $\begin{array}{l}\text { Lubrication } \\
\text { and cooling } \\
\text { system }\end{array}$ & $\begin{array}{l}\text { high-pressure water pumps, water tanks, cooling pipes, nozzles, } \\
\text { filtering devices, cooling boxes, etc. }\end{array}$ \\
\hline S06(CS) & $\begin{array}{l}\text { Electric } \\
\text { control } \\
\text { system }\end{array}$ & $\begin{array}{l}\text { relays, contactor switches/buttons, wiring of various circuits, } \\
\text { emergency stop circuits }\end{array}$ \\
\hline S07(HS) & $\begin{array}{l}\text { Auxiliary } \\
\text { system }\end{array}$ & $\begin{array}{l}\text { oil mist purification device, indicator light, machine tool guard, guide } \\
\text { rail guard, work lamp, etc. }\end{array}$ \\
\hline S08(NC) & CNC system & $\begin{array}{l}\text { CNC main board, operation panel, LCD display, servo drive of each } \\
\text { motion axis, servo motor of each motion axis, etc. }\end{array}$ \\
\hline
\end{tabular}


Table 2

Reliability scoring statistical results

\begin{tabular}{|llllll|}
\hline Subsystem name & Complexity & $\begin{array}{l}\text { Technical } \\
\text { level }\end{array}$ & $\begin{array}{l}\text { Operating } \\
\text { hours }\end{array}$ & $\begin{array}{l}\text { Environmental } \\
\text { conditions }\end{array}$ & $\begin{array}{l}\text { Impact on } \\
\text { performance of the } \\
\text { whole machine }\end{array}$ \\
\hline Basic system & 5 & 3.5 & 8.9 & 4 & 8.25 \\
\hline Spindle system & 5.9 & 4 & 7.95 & 5 & 8.05 \\
\hline Feed system & 6.75 & 4.2 & 7.08 & 4 & 8.5 \\
\hline Hydraulic system & 6.06 & 3.9 & 7.15 & 4.2 & 7.4 \\
\hline $\begin{array}{l}\text { Lubrication and } \\
\text { cooling system }\end{array}$ & 3.6 & 4.2 & 7.26 & 3.9 & 4.2 \\
\hline $\begin{array}{l}\text { Electric control } \\
\text { system }\end{array}$ & 3.8 & 3.2 & 6.9 & 3.3 & 5.1 \\
\hline $\begin{array}{l}\text { auxiliary system } \\
\text { CNC system }\end{array}$ & 2.4 & 3.7 & 6.5 & 4.7 & 2.4 \\
\hline
\end{tabular}

Table 3

Reliability score distribution

\begin{tabular}{|lllll|}
\hline Subsystem name & $\omega_{i}$ & $\mathbf{C}_{\mathbf{i}}$ & $\lambda$ & $\begin{array}{l}\text { MTBF assigned to each } \\
\text { subsystem }\end{array}$ \\
\hline Basic system & 5139.75 & 0.164 & 0.82 & 12169.858 \\
\hline Spindle system & 7551.705 & 0.241 & 1.205 & 8282.901 \\
\hline Feed system & 6824.412 & 0.218 & 1.09 & 9165.629 \\
\hline Hydraulic system & 5251.995 & 0.168 & 0.84 & 11909.766 \\
\hline $\begin{array}{l}\text { Lubrication and cooling } \\
\text { system }\end{array}$ & 1798.052 & 0.057 & 0.285 & 34787.658 \\
\hline Electric control system & 1412.104 & 0.045 & 0.225 & 44295.613 \\
\hline auxiliary system & 651.082 & 0.021 & 0.105 & 96070.949 \\
\hline CNC system & 2645.914 & 0.085 & 0.425 & 23640.238 \\
\hline Whole machine & 31275.014 & 1 & 5 & 2000 \\
\hline
\end{tabular}


Table 4

Temperature sensors layout

\begin{tabular}{|ll|}
\hline Group & Sensor location and code \\
\hline Front bearing & T1-Oil inlet; T2-Flow controller; T3-Oil outlet; \\
\hline Rear bearing & T4-Oil inlet; T5-Flow controller; T6-Oil outlet; \\
\hline Motor & T7-Oil outlet; T8-Oil inlet; \\
Others & T9-Coolant; T10-Environment ; \\
\hline
\end{tabular}

Figures

(a)

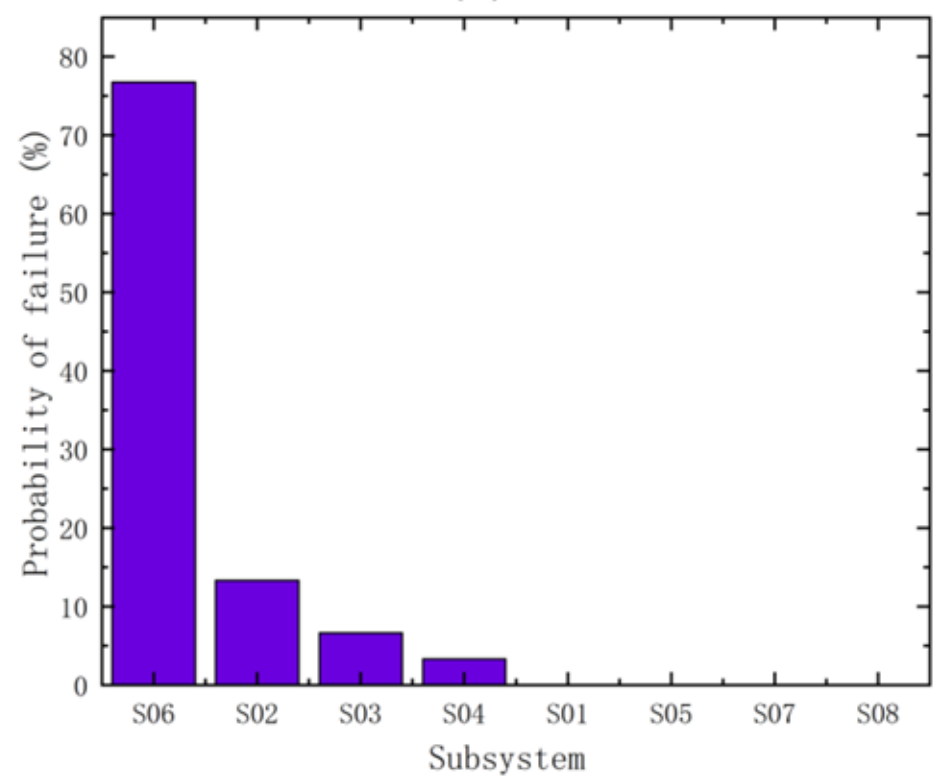

(b)

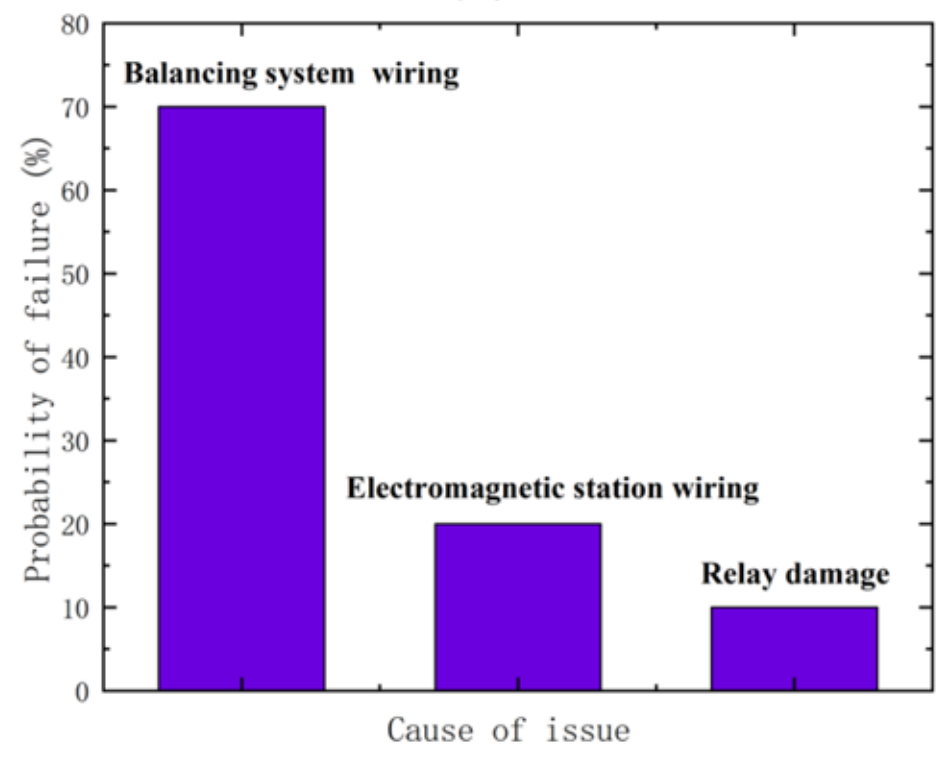

\section{Figure 1}

Failure data analysis 


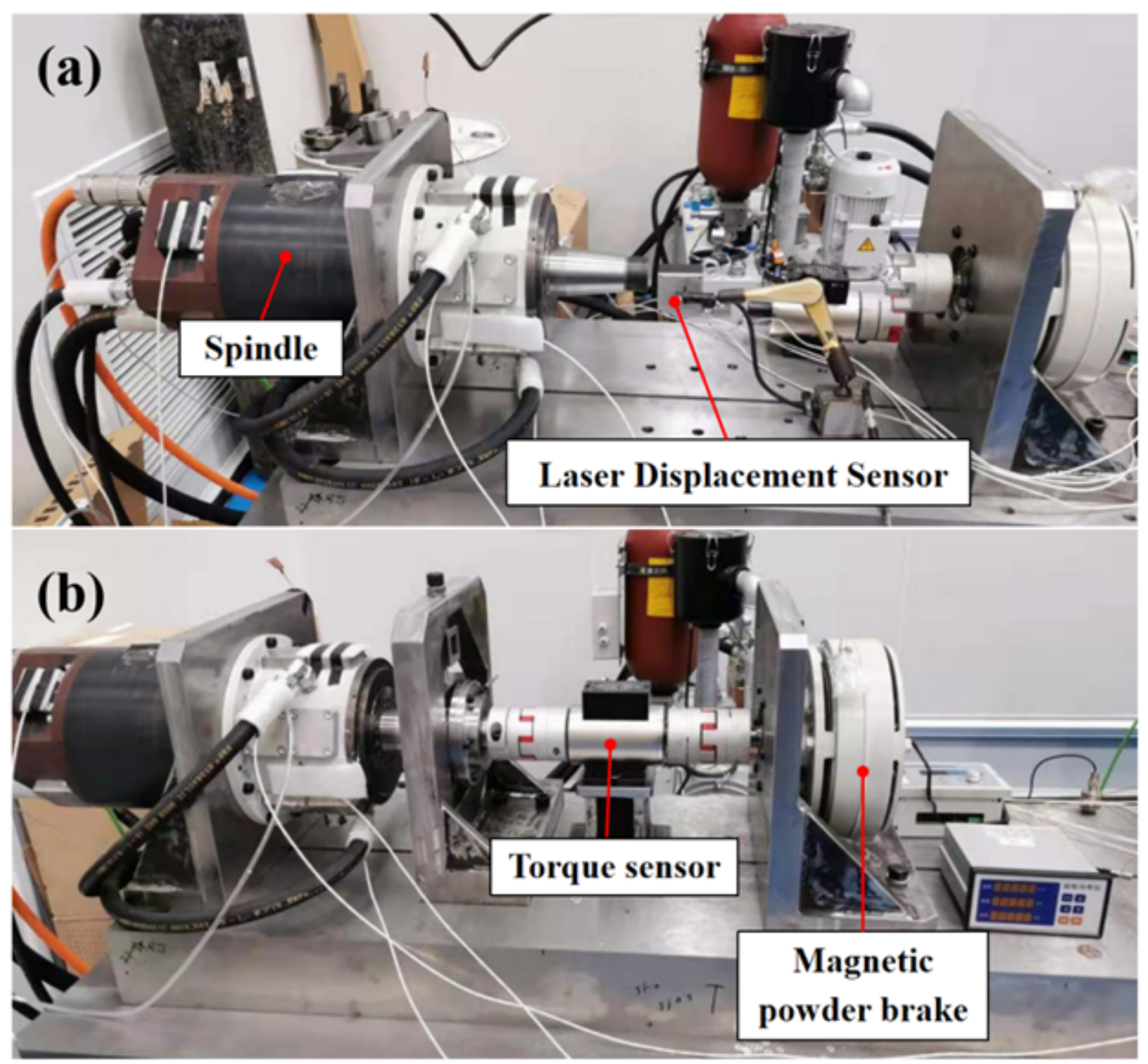

Figure 2

Experimental platform of the spindle system. 
(a)

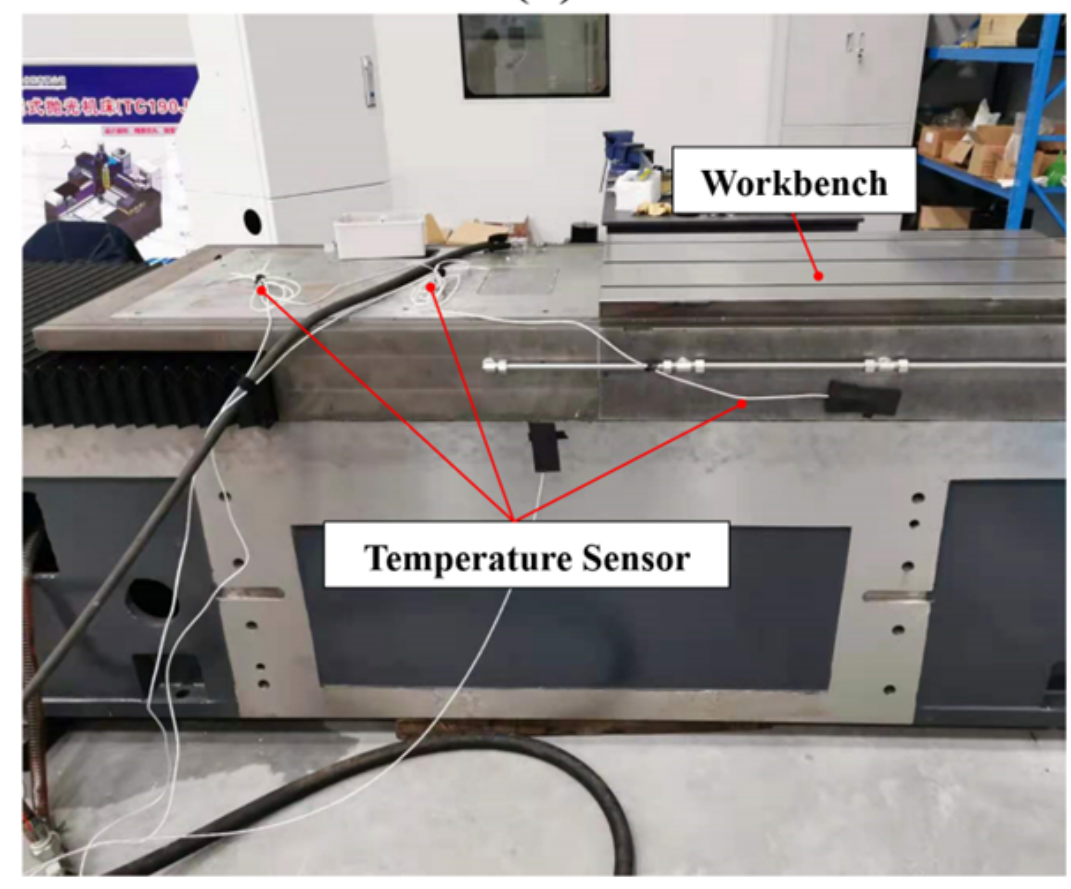

(b)

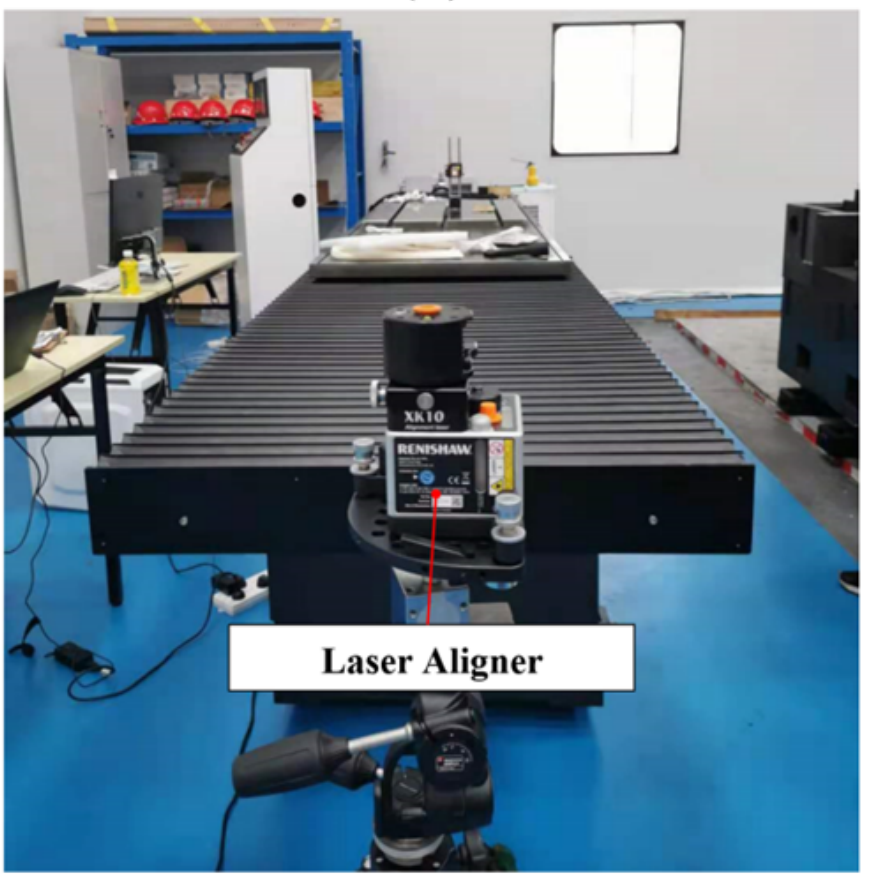

Figure 3

Experimental platform of the feed system. 


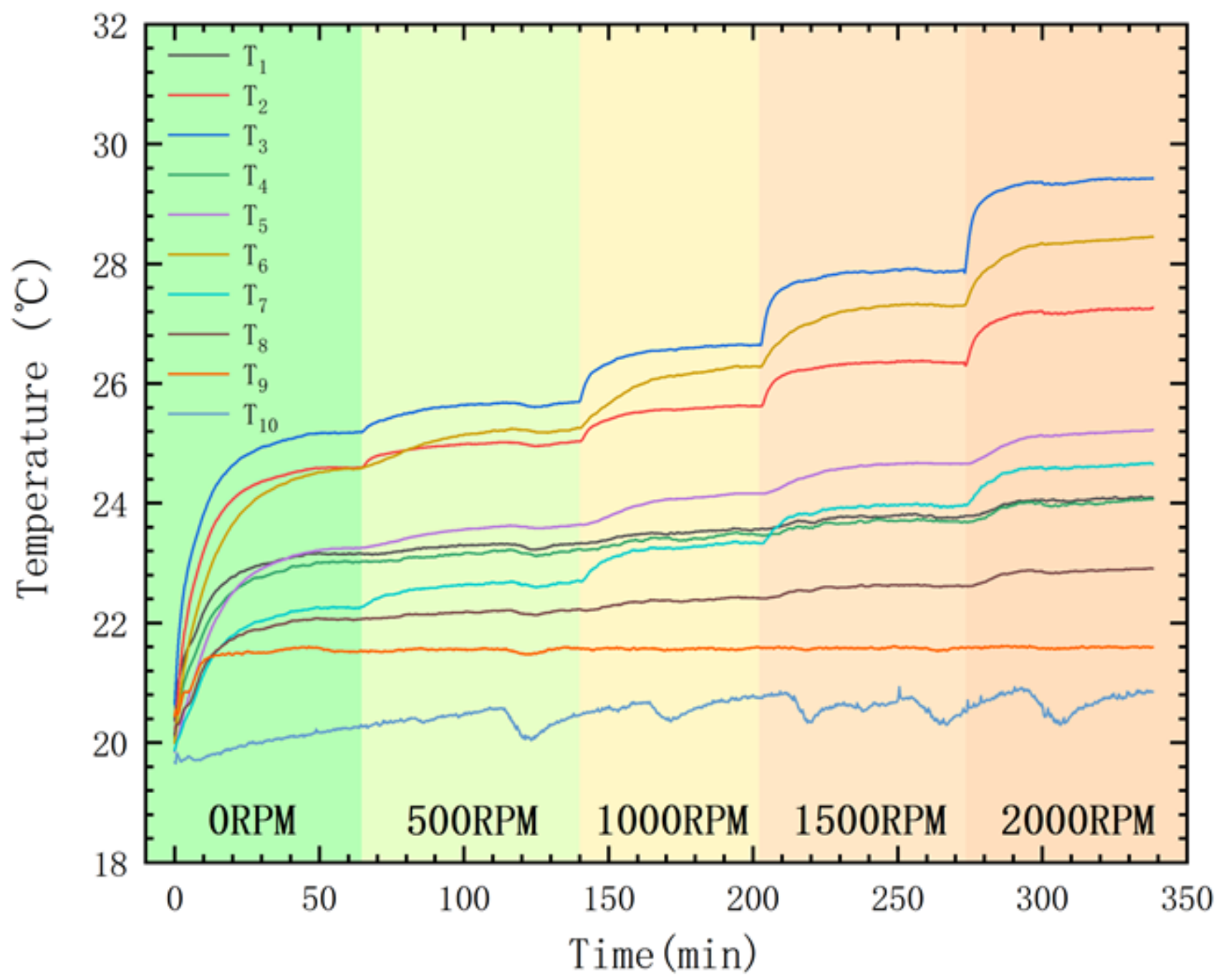

Figure 4

Temperature evolution curve. 
(a)

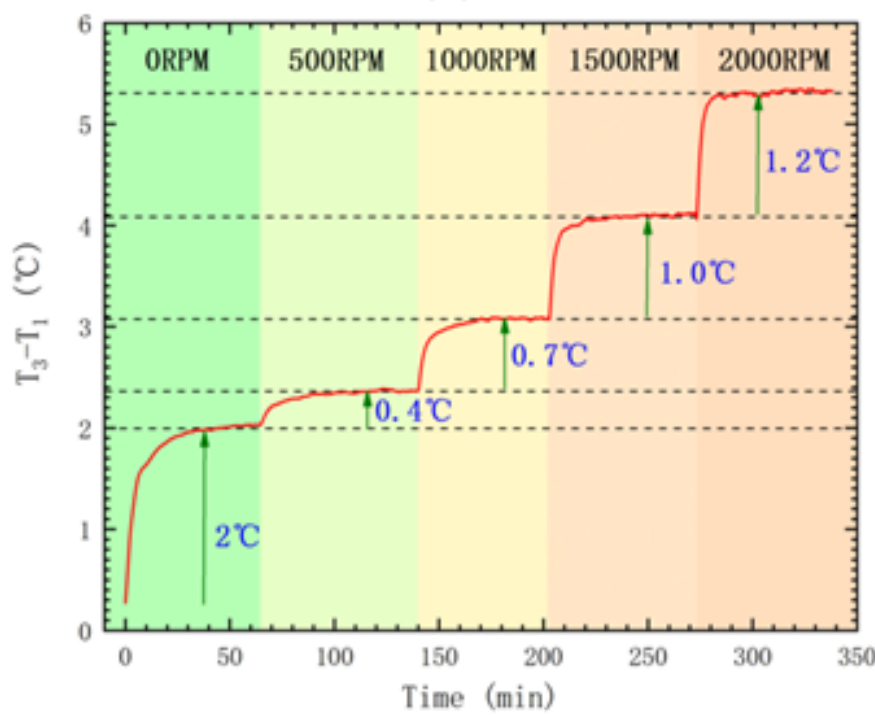

(c)

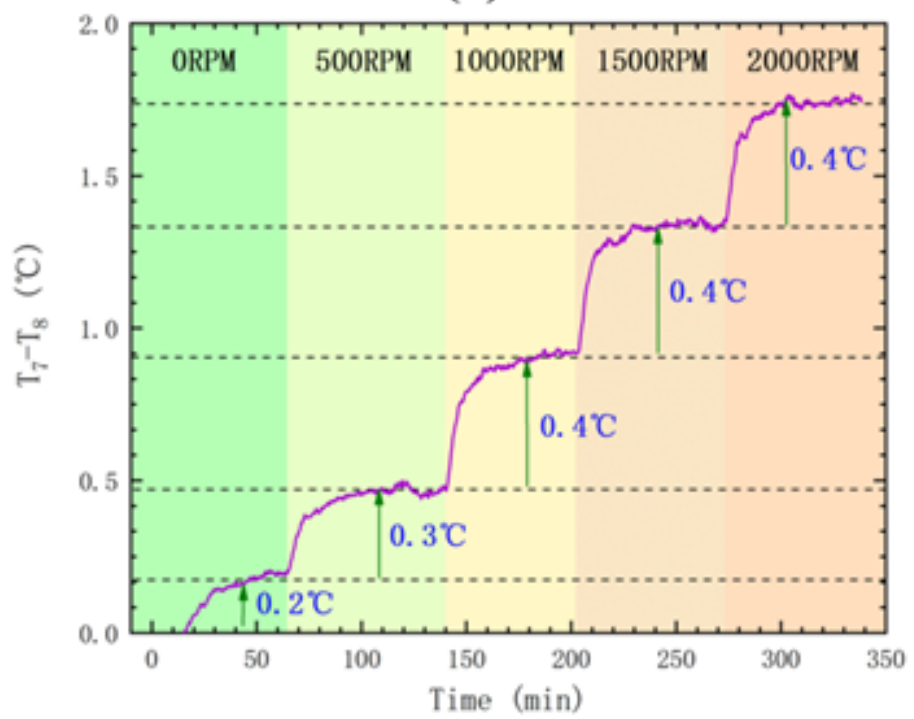

(b)

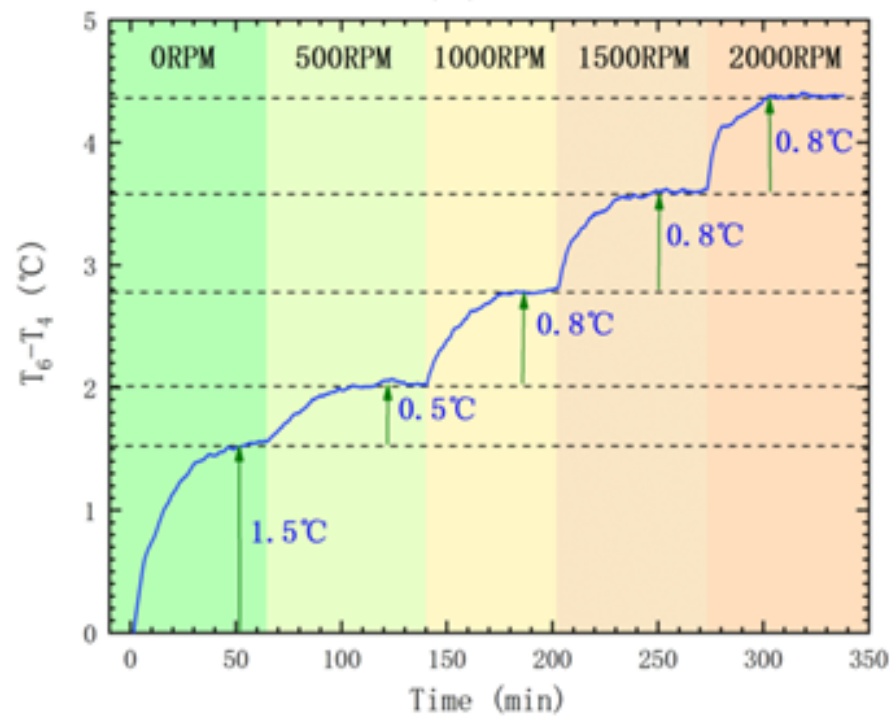

(d)

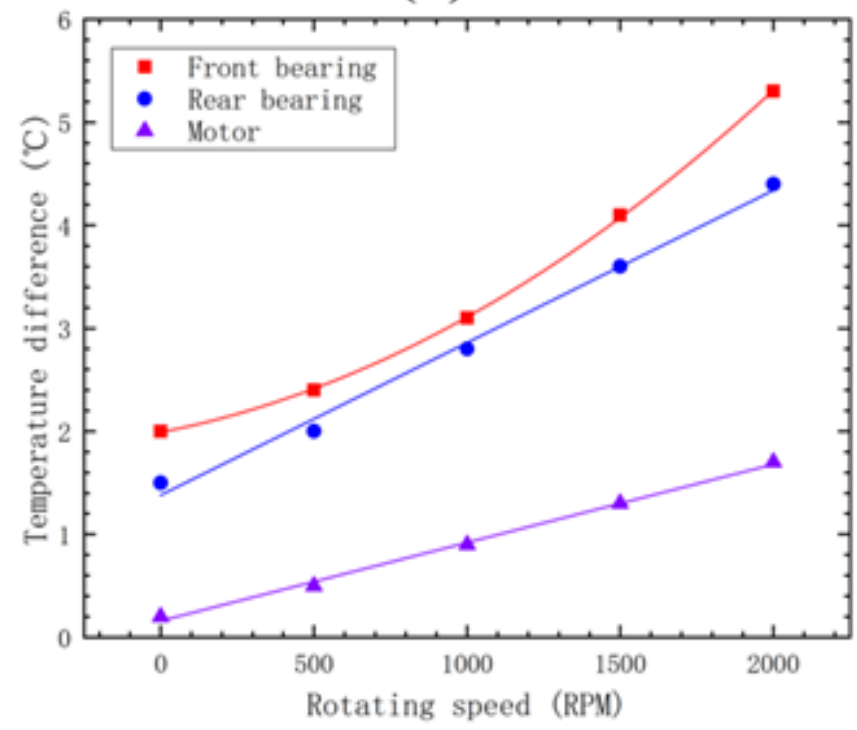

\section{Figure 5}

The temperature difference and fitting curve of each part of the spindle system. (a) Temperature difference between oil inflow (T1) and outflow (T3) at the position of the front bearing; (b) Temperature difference between oil inflow (T6) and outflow (T4) at the position of the rear bearing; (c) Temperature difference between oil inflow (T8) and outflow (T7) at the position of the motor; (d) Fitting curve of the temperature difference with rotating speed. 
(a)

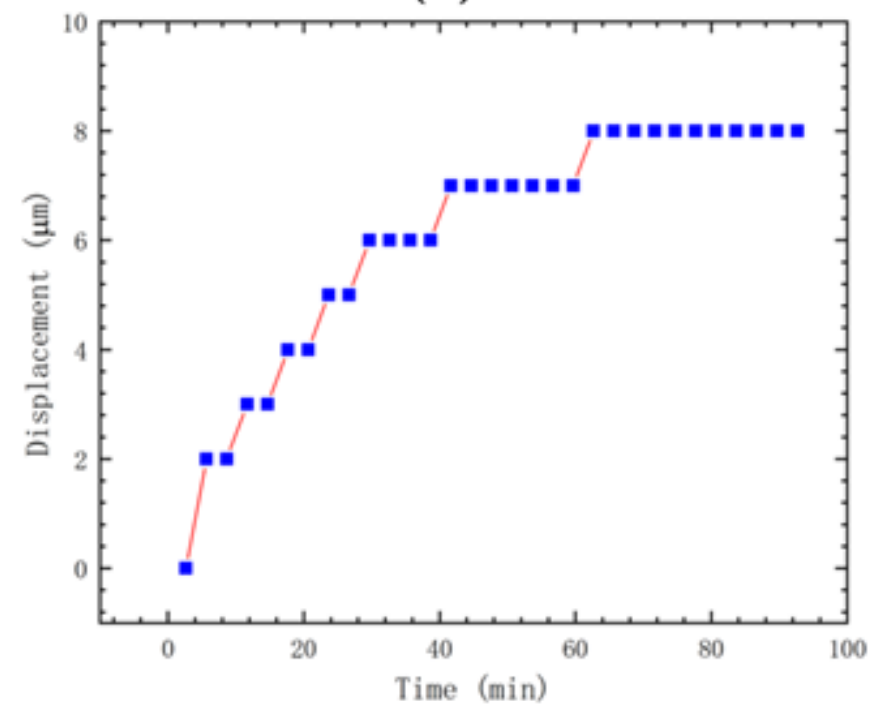

(c)

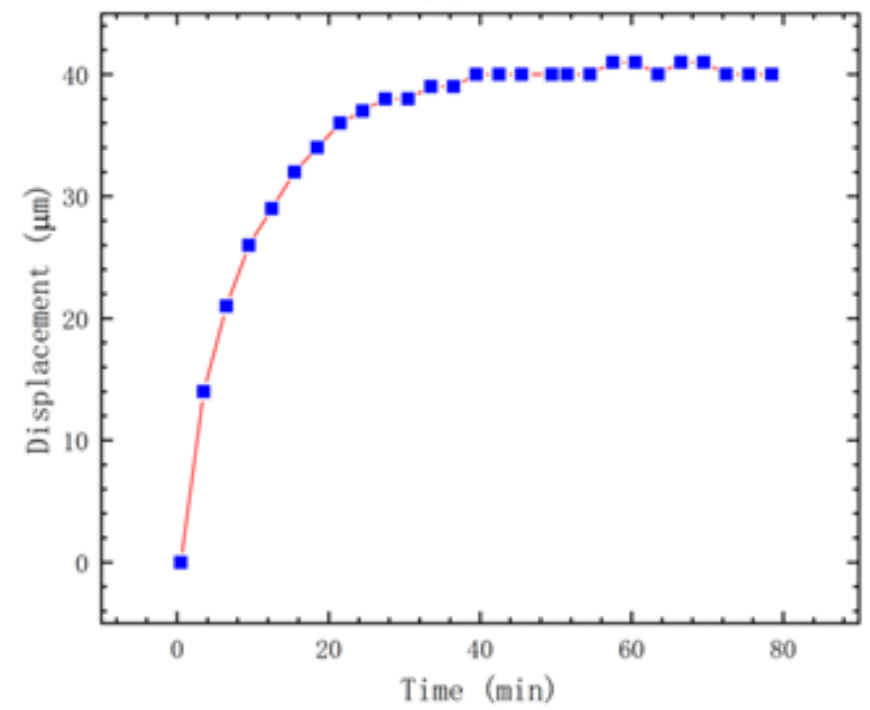

(b)

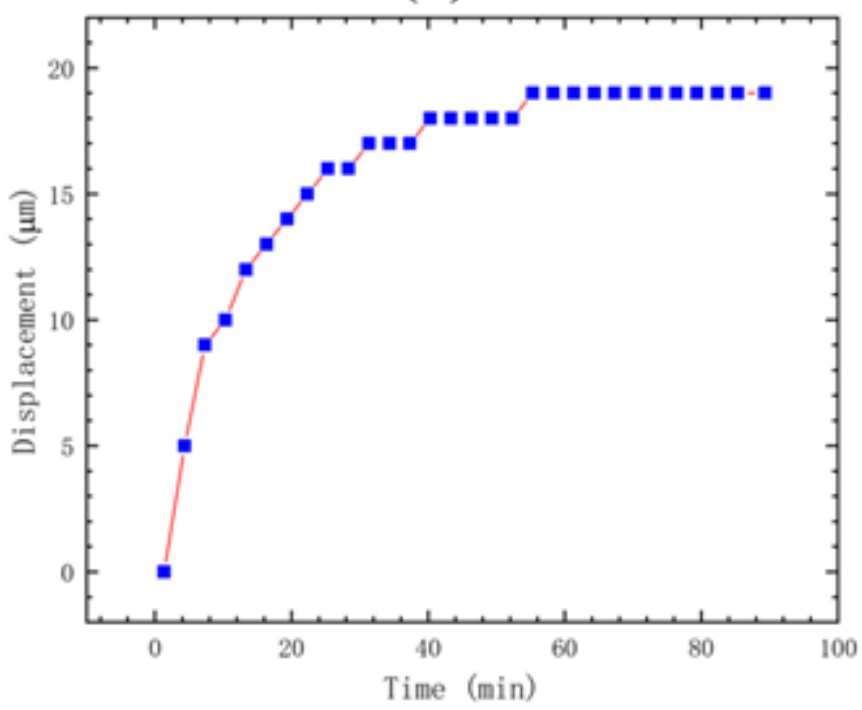

(d)

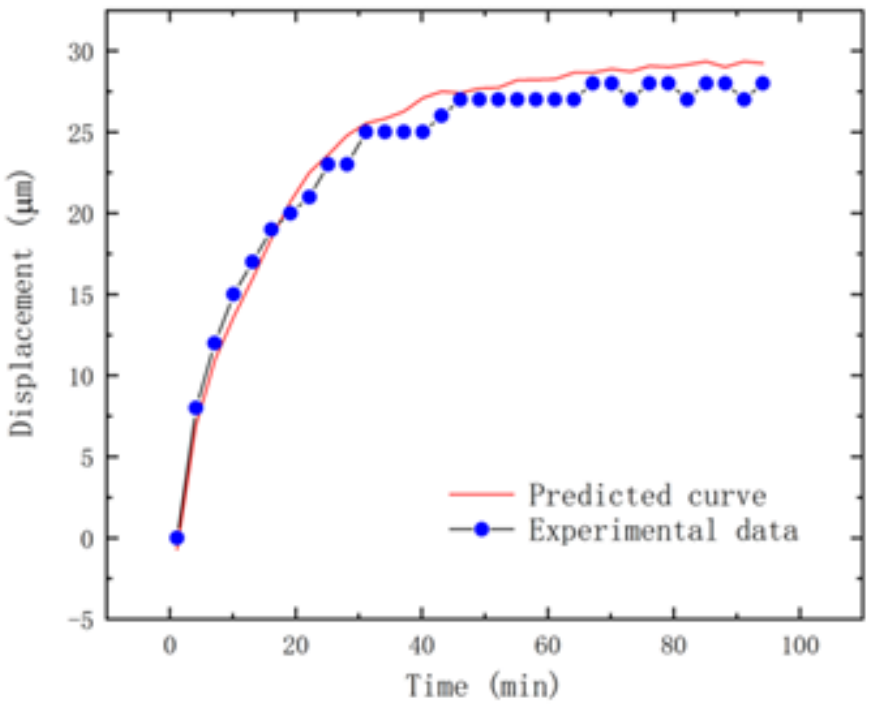

Figure 6

The axial thermal displacement at the rotating speed of (a) 1000rpm, (b) 2000rpm, (c) 3000rpm, and (c) comparison of measured data and theoretical prediction curve at the rotating speed of $2500 \mathrm{rpm}$. 
(a)

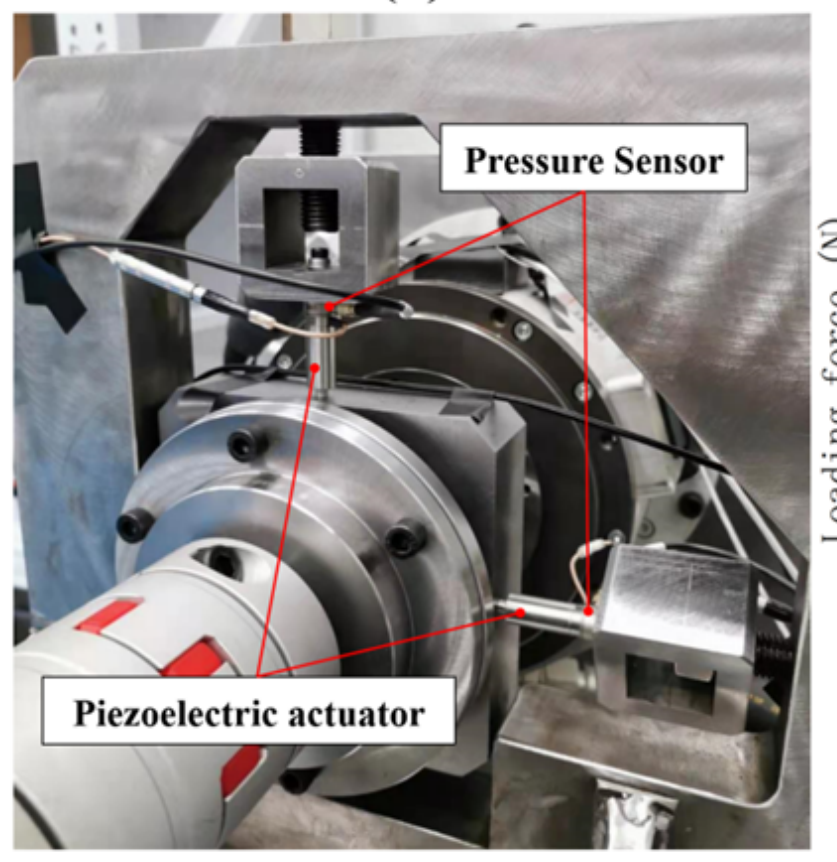

(b)

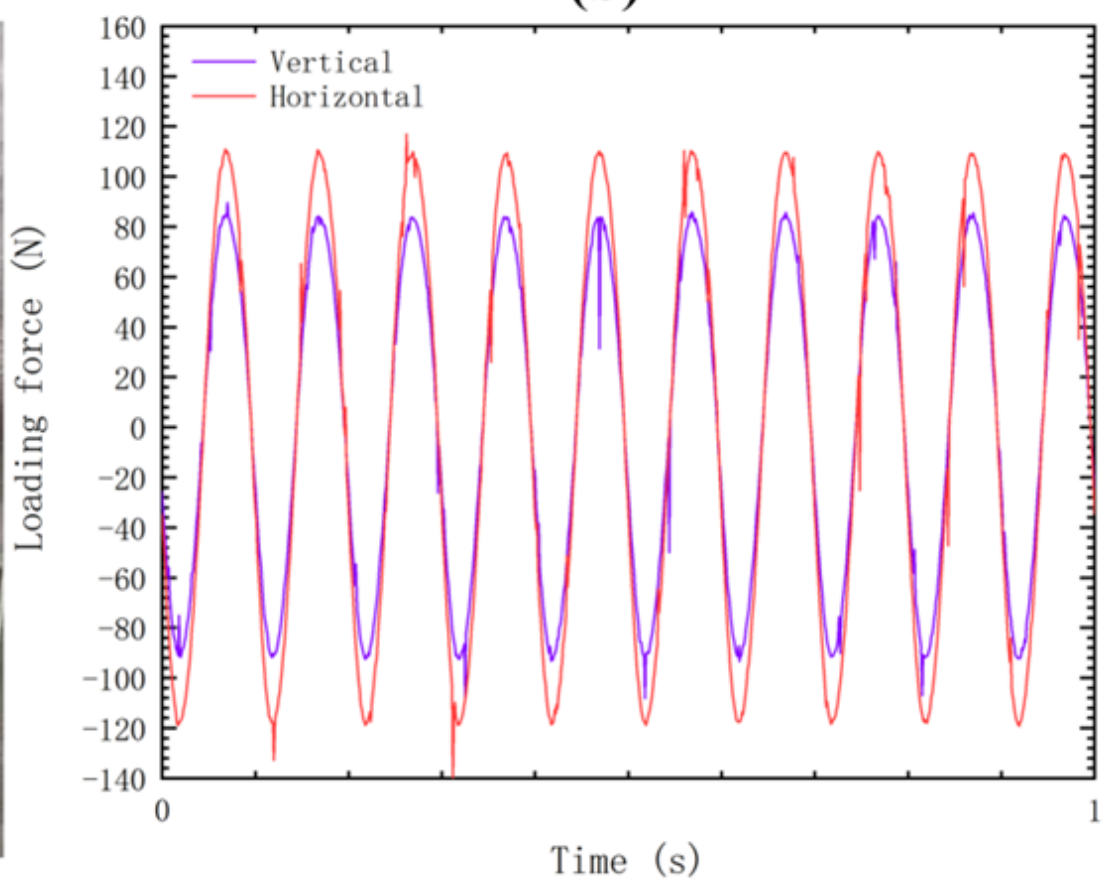

\section{Figure 7}

Loading force setup. (a) The radial force loading unit and (b) the pressure signal of the loading 
(a)
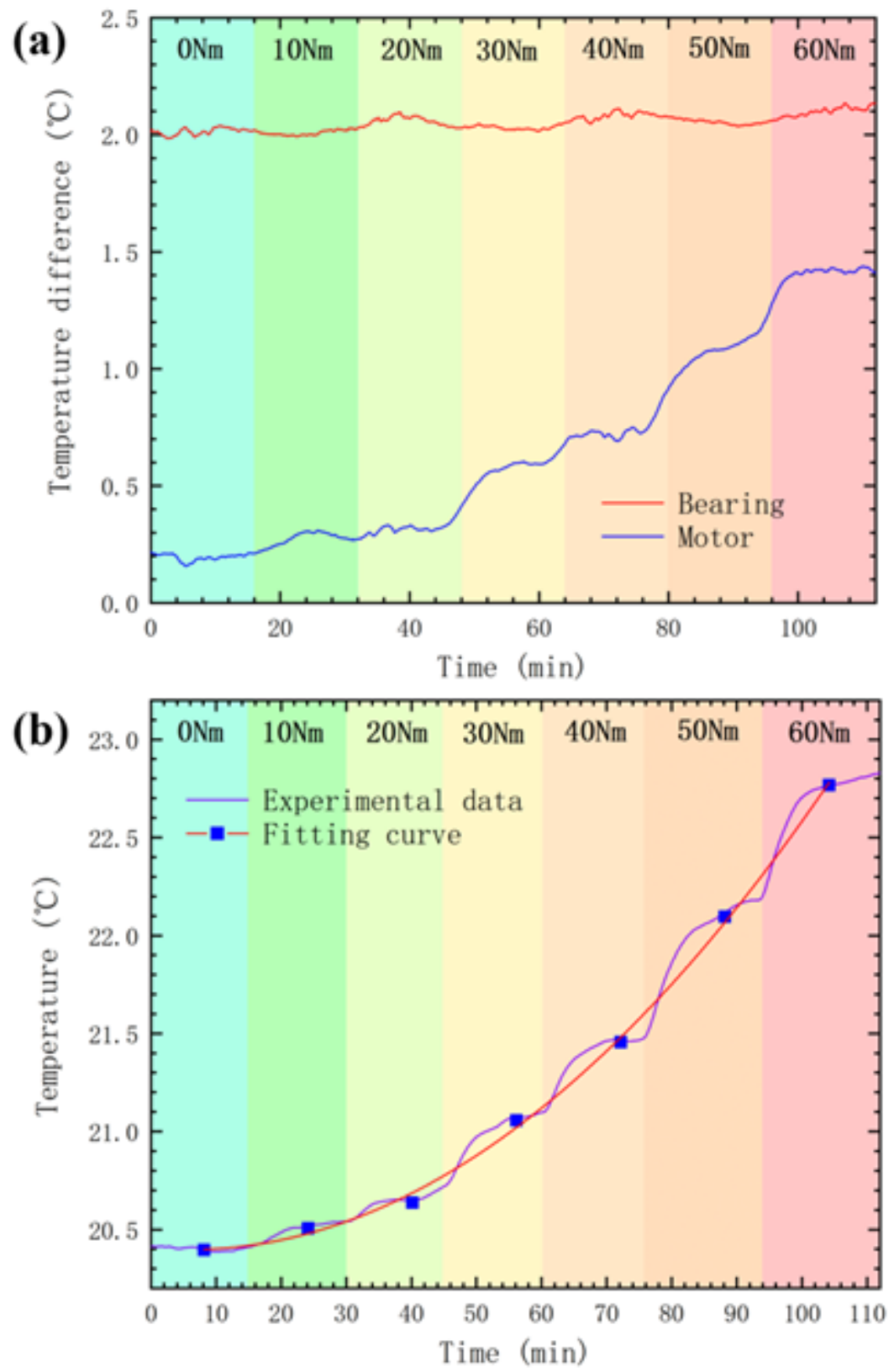

Figure 8

Temperature rising curve in the experiment. (a) Temperature difference of the oil inflow and outflow at the position of the bearing and the motor. (b) Temperature rising curve of the oil inflow and outflow of the motor. 
(a)

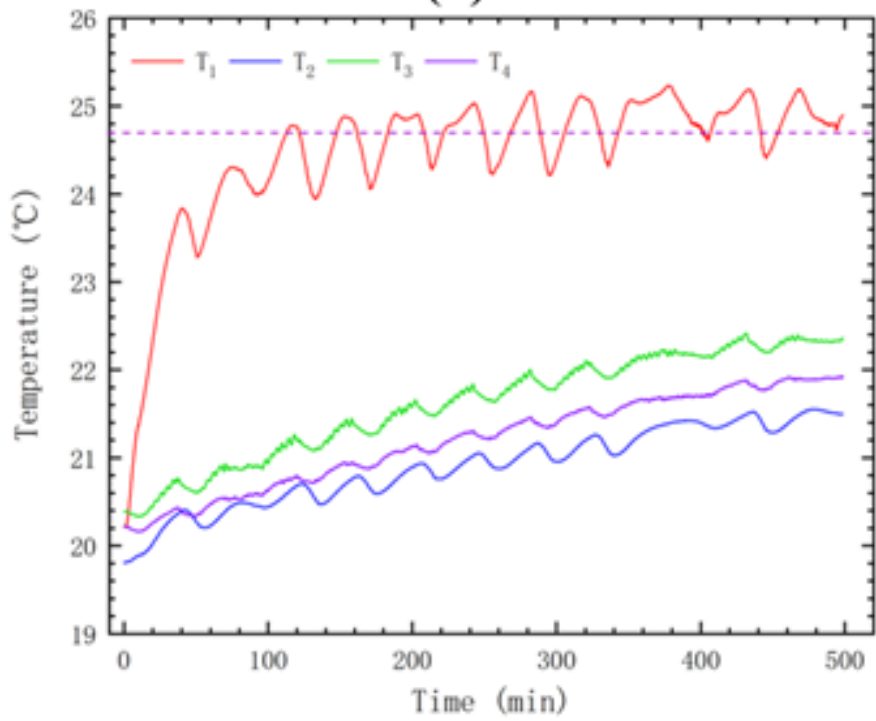

(c)

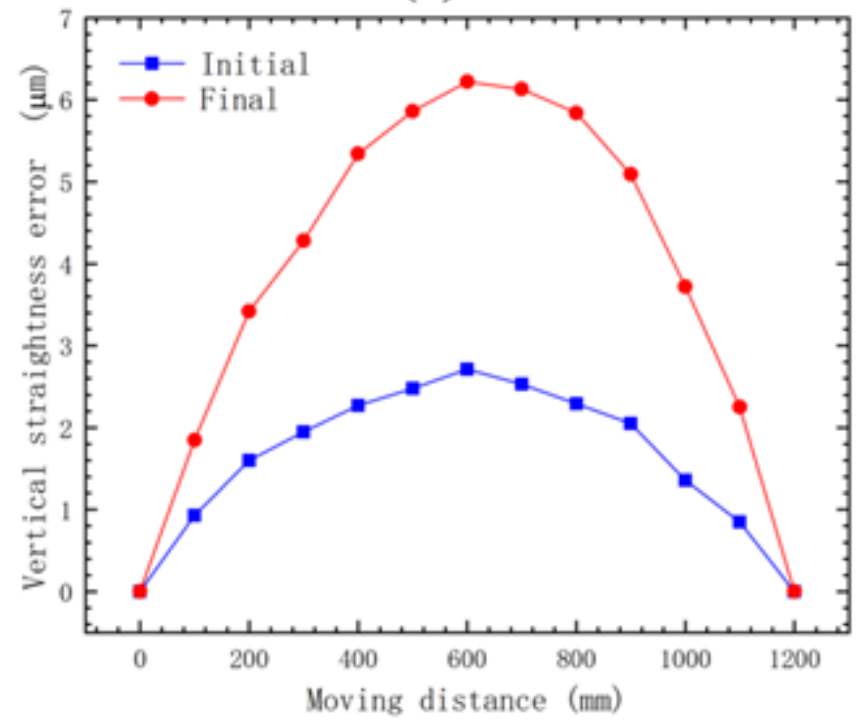

(b)

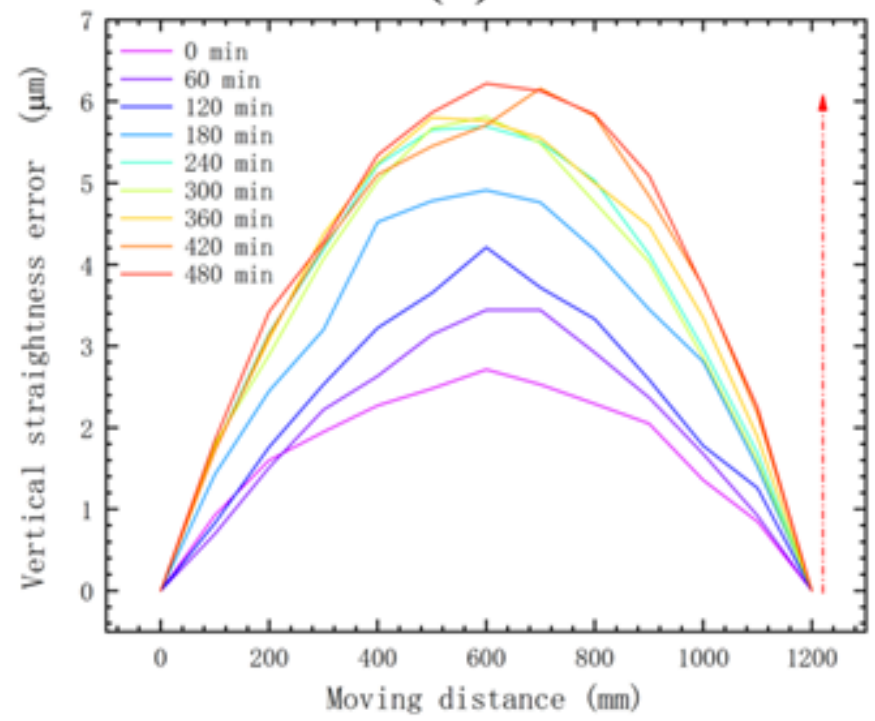

(d)

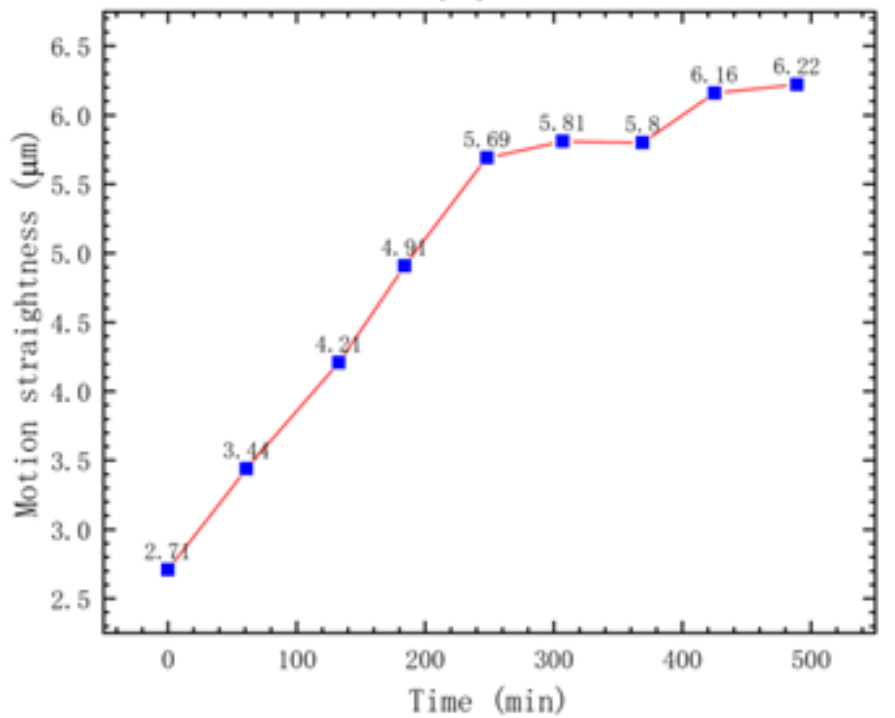

\section{Figure 9}

Experimental results of the feed system. (a) Temperature data of 4 key measuring points. (b) Vertical straightness error evolution within progressing time. (c) Initial vertical straightness and the final vertical straightness. (d) Curve of the increasing motion straightness. 